\title{
Screening of Rice (Oryza sativa L.) Genotypes for Salinity Tolerance in Ethiopia
}

\author{
Dawit Asnake ${ }^{1, ~ *}$, Hussien Mohammed ${ }^{2}$ \\ ${ }^{1}$ Wheat Breeding and Genetics, Kulumsa Agricultural Research Center, Assela, Ethiopia \\ ${ }^{2}$ Department of Plant and Horticultural Sciences, Hawassa University, Hawassa, Ethiopia
}

Email address:

apari199@yahoo.com (D. Asnake), aamina68@yahoo.com (H. Mohammed)

${ }^{*}$ Corresponding author

\section{To cite this article:}

Dawit Asnake, Hussien Mohammed. Screening of Rice (Oryza sativa L.) Genotypes for Salinity Tolerance in Ethiopia. International Journal of Applied Agricultural Sciences. Vol. 3, No. 1, 2017, pp. 25-31. doi: 10.11648/j.ijaas.20170301.13

Received: December 27, 2016; Accepted: January 9, 2017; Published: March 6, 2017

\begin{abstract}
This study was carried out to investigate the effect of 4 different salinity levels $\left(0,4,8\right.$ and $\left.12 \mathrm{dSm}^{-1}\right)$ on yield of 13 rice genotypes along with a salt-tolerant and susceptible check genotypes to identify salt tolerant rice genotype to be used under irrigation. A factorial combination of the fifteen genotypes and four salinity levels was laid out in completely randomized design (CRD) in two replications in a mesh house. The experiments were conducted at Werer Agricultural research Center, eastern Ethiopia, from December, 2008 to May, 2009. Since all plants of all genotypes died under salinity level of 12 $\mathrm{dSm}^{-1}$, grain yield data obtained from three salinity levels are included in the analysis. Statistical Analysis of Variance (ANOVA) revealed highly significant difference among the test genotypes in all traits studied, witnessing the availability of ample genetic variability which can be used in breeding rice for tolerance to salinity. Salinity levels affected all measured traits. The Genotype x Salinity interaction was also significant for all traits except for Plant Height during Heading, Panicle Length, Number of Panicle, Number of Grains per panicle and Number of Tillers per plant, indicating the inconsistency of the performance of genotypes by many of the traits over the salinity levels and the need for selection of rice genotypes specifically adapted to a particular salinity level. In the pot experiment an increase in salinity from 0 to 4 and to $8 \mathrm{dSm}^{-1}$ consistently reduced growth parameters, biomass, grain yield and its components, but delayed phenology. Genotypes IR66946-3R-176-1-1 (G15) and IR68144-2B-2-2-3-2 (G8) were tolerant to salinity both during early growth and later during vegetative growth, and seed setting. IR59418-7B-21-3 (G1), IR59418-7B-27-3 (G2) and IR72593-B-18-2-2-2 (G13) were found to be salt tolerant during vegetative growth and seed setting. These five genotypes can therefore be recommended for further testing under salt stress. Higher grain yield and its components under salt stress and smaller reduction of these parameters under salt stress as compared with values under normal growth condition should be used as selection criteria to develop salt tolerant rice genotypes. AMMI biplot analysis enabled clear discrimination of genotypes response against root zone salinity stress.
\end{abstract}

Keywords: Salinity, Tolerance, Rice, Genotype

\section{Introduction}

Irrigated land is only $15 \%$ of total cultivated land, but as irrigated land has at least twice the productivity of rainfed land, it may produce one-third of the world's food [20]. Irrigated agriculture, however, is accompanied with the problem of salinity. Soil salinity has become a major factor limiting crop productivity worldwide, especially in arid and semiarid regions. In general, salt affected soils have very low productivity because of dominance of the soluble salts (salinity) and /or exchangeable $\mathrm{Na}+$ ions. Salinity affects $7 \%$ of the world's land area, which amounts to 930 million hectares [24]. In Ethiopia, previous reports indicated that more than 11,000,000 ha of arable land has been affected by salinity and it is the first in Africa. Considerable area of land has been abandoned for cultivation due to the prevalence of salt affected soils at the Middle Awash [6]. Furthermore, recent reports also indicate that $39 \%$ of the Abaya State Farm is salt affected [17]. These figures indicate the magnitude of the problem that must be tackled in order to meet future national food needs of the increasing population. Efforts 
should be directed towards improving the level of management of soils already under cultivation, and by bringing new areas of the dry land ecosystems, under cultivation. Therefore, solutions that include agronomic and breeding approaches for efficient utilization of such soils have to be devised.

Rice became a potential cereal crop which can be used for food and feed in the arid and semi-arid environments. Under lowland irrigated conditions, it can give 6-8 tons per hectare. The recent surge in demand for rice combined with the sky rocketing import price challenged the country's policy makers to seriously consider the country's potential to grow the grain for itself. Subsequently, successful lobbying has pushed rice to be named as "a millennium crop". This favors rice research and promotion on a large scale. Moreover, some research activities on developing well-adapted and high yielding rice genotypes for lowland irrigated areas are currently under way.

Breeding crops for salt tolerance would be likely to provide economic and efficient methods of overcoming problems of saline soils. Such a crop improvement and selection program must be based on adequate variability for salinity tolerance and such variation has been observed within species. Rice is sensitive to salinity like other cereal crops, this limiting its production under salinity prone areas; however, cultivar differences were observed for salt tolerance in rice. Rice breeders have used such genetic variability to produce high yielding and salt tolerant cultivars. Screening efforts are also being made in different parts of the world exploiting this diverse genetic potential to identify rice genotypes tolerant to salinity $[21,8,16]$. However, in Ethiopia little has been done to identify rice genotypes adaptable to adverse soil conditions such as salinity and to investigate morphological characters associated with grain yield under salt stress. This study, was therefore, conducted to identify rice genotypes with sufficient tolerance and adaptation to salinity; and to assess the nature and magnitude of the existing genotype $\mathrm{X}$ salinity interaction under irrigated condition.

\section{Material and Methods}

\subsection{Field Experimental Set-Up}

The study was carried out during 2008 growing season at Werer Agricultural Research Center (WARC), which is 280 $\mathrm{km}$ North East of Addis Ababa. It is located at $9^{\circ} 60^{\prime} \mathrm{N}$ latitude and $40^{\circ} 9^{\prime}$ 'E longitude and at an altitude of 740 meter above sea level. Light textured alluvial soil with a $\mathrm{pH} 7.1$ to 8.4 is the soil type of the centre [25]. The soil organic matter varies from 0.46 to $2.08 \%$ in the surface soil $(0-30 \mathrm{~cm})$. The mean annual temperature is $34^{\circ} \mathrm{C}$ while the mean annual rainfall and evapo-transpiration are, $560 \mathrm{~mm}$ and $2600 \mathrm{~mm}$, respectively. The weather is very hot and dry and rainfall is very erratic [25].

Fifteen rice genotypes, which were developed by International Rice Research Institute (IRRI) particularly for salt tolerance, were assessed at four levels of salinity $(0,4,8$ and $\left.12 \mathrm{dSm}^{-1}\right)$. The rice genotypes used in the study are given in Table 1. Soil collection and preparation: For this pot experiment, soils were collected from Werer Agricultural Research center. The soils were air dried for 10 days followed by crushing, mixed thoroughly and sieved through a $2 \mathrm{~mm}$ sieve. The $\mathrm{pH}$ value, cation exchange capacity (CEC) and electrical conductivity (EC) of the soil were $7.4,14.78$ meq $/ 100 \mathrm{~g}$ soil and $1.02 \mathrm{dSm}^{-1}$, respectively. The amount of $\mathrm{NaCl}$ which were applied corresponding to the four salinity levels was calculated and these values were: 12.8, 25.6 and $38.4 \mathrm{~g} \mathrm{NaCl}$ per $5 \mathrm{~kg}$ soil, corresponding 4,8 and $12 \mathrm{dSm}^{-1}$.

Table 1. Test entries for the screening experiment with code, designation, pedigree, origin and their features.

\begin{tabular}{|c|c|c|c|c|}
\hline Code & Designation & Pedigree & Origin & Feature \\
\hline G1 & IR59418-7B-21-3 & IR10198-66-2/IR32429-47-3-2-2/AT401 & IRRI & Early maturing \\
\hline $\mathrm{G} 2$ & IR59418-7B-27-3 & IR10198-66-2/IR32429-47-3-2-2/AT 69-5 & IRRI & Early maturing \\
\hline G3 & IR61247-3B-8-2-1 & BG367-4/AT69-5 & IRRI & Early maturing \\
\hline G5 & IR68652-3B-22-3 & IR20/POKKALI B & IRRI & Early maturing \\
\hline G6 & IR69588-4R-P-3-3 & IR 26//IR 20/POLKALI B & IRRI & Early maturing \\
\hline G7 & IR70870-B-P-2-2 & POKKALI B/IR20/IR 26 & IRRI & Early maturing \\
\hline G9 & IR68144-2B-2-2-3-3 & IR 72/ZAWA BONDAY & IRRI & Early maturing \\
\hline G10 & IR72593-B-13-1-3-1 & IR65195-3B-13-2-3//IR 20/IR 24 & IRRI & Early maturing \\
\hline G11 & IR72593-B-13-3-2-1 & IR65195-3B-13-2-3//IR 20/IR 24 & IRRI & Early maturing \\
\hline G12 & IR72593-B-13-3-3-1 & IR65195-3B-13-2-3//IR 20/IR 24 & IRRI & Early maturing \\
\hline G13 & IR72593-B-18-2-2-2 & IR65195-3B-13-2-3//IR 20/IR 24 & IRRI & Early maturing \\
\hline G14 & IR29 & IR 833-6-2-1-1//IR 1561-149-1//IR24 *4 / O. NIVARA & IRRI & Early maturing \\
\hline G15 & IR66946-3R-176-1-1 & IR29/POKKALI B & IRRI & Early maturing \\
\hline
\end{tabular}

NB: G14 and G15 standard susceptible and tolerant genotypes, respectively

The experiment was conducted by raising plants in plastic pots of $25.4 \mathrm{~cm}$ top diameter, $14.6 \mathrm{~cm}$ bottom diameter and $21.6 \mathrm{~cm}$ depth filled with $5 \mathrm{~kg}$ sundried soil. Each pot was planted with ten seeds of each genotype. The pots were lined with doubled layer of cotton to restrict seepage of soil solution and kept in a mesh house under sunlight. Thereafter, the soil in the pots was moistened with water and commercial $\mathrm{NaCl}$ salt was added in each pot according to the treatments. 
Salt solution seepage was collected every 24 hours from each pot and returned to the pots to avoid seepage loss of salts. Weeds grown in the pots were removed by hands. Watering was done, as often as necessary, in each pot to hold the soil water level optimum.

\subsection{Data Collection and Analysis}

For this particular study, grain yield dataset were subjected to analysis of variance (ANOVA) for two factor completely randomized design using the General Linear Model (GLM) procedure of the SAS statistical analysis system [22]. Stability analysis was performed using SAS to calculate stability parameters like Wricke's ecovalence (W), MUIRSTAB, heterogeneity of variances (HETERO), Lack of correlation (LACK-CORR) and variances of ranks, $\mathrm{Si}^{(2)}$. Moreover, global chi-square test was employed to check whether variances of the ranks, $\mathrm{Si}^{(2)}$, are significant or not. Based on grain yield data where each salinity level was considered as environment, GxE interaction was analyzed using additive main effects and multiplicative interaction (AMMI) biplot analysis to assess similarity and dissimilarity among three salinity levels and interaction patterns between genotypes and salinity levels.

\section{Results and Discussion}

Analysis of variance revealed that grain yield plant ${ }^{-1}$ of 15 tested rice genotypes differed significantly $(\mathrm{p} \leq 0.01$, Table 2). Genotypes IR66946-3R-176-1-1 (G15), IR72593-B-18-22-2 (G13), IR59418-7B-21-3 (G1), IR59418-7B-27-3 (G2), and IR68144-2B-2-2-3-2 (G8) were genotypes with the highest mean grain yield per plant of $4.37 \mathrm{~g}, 3.67 \mathrm{~g}, 3.66 \mathrm{~g}$, $3.38 \mathrm{~g}$, and $2.92 \mathrm{~g}$, respectively, across the three root zone salt concentrations. Average reduction in grain yield plant ${ }^{-1}$ over the two salinity levels ( 4 and $8 \mathrm{dSm}^{-1}$ ) as compared to the control of these genotypes ranged between 36 for IR594187B-27-3 (V2) to 56\% for IR72593-B-18-2-2-2 (V13) while for susceptible genotype, IR29 (G14) and IR72593-B-13-3-31 (G12) this reduction was 74 and $70 \%$, respectively. These genotypes with lowest reduction are all found to be promising genotypes for salt tolerance and over all adaptation. Genotype with the lowest mean grain yield per plant was genotype IR68652-3B-22-3 (G5) with mean grain yield plant $^{-1}$ of $2.10 \mathrm{~g}$.

Table 2. Mean squares from analysis of variance of 15 genotypes grown in control and two NaCl salinity levels for germination study.

\begin{tabular}{|c|c|c|c|c|c|}
\hline Parameters & Genotype $(\mathrm{df}=14)$ & Salinity $(d f=2)$ & $G * S(d f=28)$ & Error $(d f=45)$ & CV (\%) \\
\hline Number of panicle & $76.987 * * *$ & $707.24 * * *$ & $16.84 \mathrm{~ns}$ & 10.49 & 25.00 \\
\hline Number of grains panicle ${ }^{-1}$ & $151.14 * * *$ & $3321.03 * * *$ & $29.23 \mathrm{~ns}$ & 20.92 & 13.23 \\
\hline Number of spikelet panicle- ${ }^{1}$ & $6.83 * * *$ & $270.76^{* * *}$ & $1.995 * *$ & 0.946 & 6.51 \\
\hline 100-grain weight & $0.3346 * * *$ & $4.313 * * *$ & $0.241 * * *$ & 0.0141 & 6.645 \\
\hline Grain yield per plant & $2.67 * * *$ & $65.73 * * *$ & $0.47 *$ & 0.253 & 18.26 \\
\hline Spikelet fertility & $403.38 * * *$ & $224.4^{*}$ & $155.79 * * *$ & 58.48 & 15.92 \\
\hline
\end{tabular}

Where; ns $=$ non-significant $* * *$ and $* * *$ significant at $5 \%, 1 \%$ and 0.01 probability level, respectively

Table 3. Contribution of each genotype to rank change and heterogeneity of variances in grain yield (GYPP).

\begin{tabular}{|c|c|c|c|c|c|c|}
\hline \multirow{2}{*}{ VAR } & \multicolumn{6}{|l|}{ Statistics } \\
\hline & VARMEAN & $\mathbf{W}$ & MUIRSTAB & HETERO & LACKCORR & SI $^{2}$ \\
\hline G1 & 3.76222 & 0.36026 & 0.39567 & 0.33816 & 0.05751 & 33.3333 \\
\hline G2 & 3.38296 & 0.50228 & 0.46668 & 0.40866 & 0.05803 & 52.3333 \\
\hline G3 & 2.23630 & 0.16096 & 0.29602 & 0.25328 & 0.04275 & 9.3333 \\
\hline G4 & 2.49109 & 0.05436 & 0.24272 & 0.16352 & 0.07920 & 7.0000 \\
\hline G5 & 2.07600 & 0.01538 & 0.22323 & 0.17277 & 0.05047 & 4.3333 \\
\hline G6 & 2.30889 & 0.55174 & 0.49141 & 0.40260 & 0.08881 & 37.3333 \\
\hline G7 & 2.26770 & 0.06115 & 0.24612 & 0.17193 & 0.07418 & 19.0000 \\
\hline G8 & 2.91490 & 0.00218 & 0.21663 & 0.16327 & 0.05337 & 3.0000 \\
\hline G9 & 2.25396 & 0.19872 & 0.31490 & 0.23338 & 0.08152 & 25.3333 \\
\hline G10 & 2.26489 & 0.08192 & 0.25650 & 0.17182 & 0.08468 & 17.3333 \\
\hline G11 & 2.43333 & 0.13938 & 0.28523 & 0.17926 & 0.10597 & 25.3333 \\
\hline G12 & 2.40563 & 0.31103 & 0.37106 & 0.27850 & 0.09256 & 34.3333 \\
\hline G13 & 3.66430 & 2.56390 & 1.49749 & 0.98634 & 0.51116 & 61.0000 \\
\hline G14 & 2.67837 & 1.41700 & 0.92404 & 0.79698 & 0.12706 & 61.0000 \\
\hline $\mathrm{TSS}^{\#}$ & & 6.46628 & & 4.88343 & 1.58284 & \\
\hline \multirow{2}{*}{\multicolumn{2}{|c|}{ GCSQUT $^{\$}$}} & S1SUM & SSVXE & PVALUE & & \\
\hline & & 396.333 & 6.46628 & 0.0000 & & \\
\hline
\end{tabular}

\# Total sums of squares due to heterogeneity among variances and imperfect correlation ${ }^{\$}$ Global chi-square test for difference between genotypes in stability

Moreover, grain yield per plant was decreased significantly $(p \leq 0.01)$ due to the effect of increased levels of salinity (Table 2). The mean grain yield ranged from $1.45 \mathrm{~g}$ to $4.35 \mathrm{~g}$. The maximum value $(4.35 \mathrm{~g})$ of grain yield plant-1 was obtained at control treatment and the minimum value $(1.45 \mathrm{~g})$ was recorded at the highest salinity level, $8 \mathrm{dSm}^{-1}$ (Table 3 ). The correlation between grain yield and salinity levels was also negative and significant $(r=-0.982, p \leq$ 
0.0001). An increase in salt concentration from the control to $4 \mathrm{dSm}^{-1}$ significantly decreased grain yield plant-1 by $44.4 \%$. A further increase of salt concentration to $8 \mathrm{dSm}^{-1}$ reduced grain yield plant-1 by $66.7 \%$. The reduction in grain yield plant-1 of $22.3 \%$ between salt concentrations of 4 and $8 \mathrm{dSm}^{-1}$ was also statistically significant. Between salinity levels of the control and $8 \mathrm{dSm}^{-1}$, grain yield plant-1 was reduced more than 3-fold (by 66.7\%). Regression of the mean grain yield plant- 1 on the salinity levels shows that each $1 \mathrm{dSm}^{-1}$ increase in salt concentration will reduce grain yield per plant by $0.36 \mathrm{~g}$ in salinity range between the control and $8 \mathrm{dSm}^{-1}$.

The existence of significant $(\mathrm{p} \leq 0.05)$ Genotype $\mathrm{x}$ Salinity interaction effect on grain yield plant ${ }^{-1}$ was also confirmed from ANOVA (Table 2). This revealed differential reaction of genotypes to stress at different salinity levels. Further analyses were made partitioning the significant GxS component in to variance heterogeneity and lack of correlation. Extended analysis of results showed that the Genotype $x$ Salinity interaction due to rank change (LACKCORR) and due to change of scale (HETERO) are not equal, witnessing the fact that contribution of variance heterogeneity of genotypes is much more than the inconsistent ranks of the genotypes (Table 3). For instance, using Wricke's ecovalence (W), genotypes IR59418-7B-21-3 (G1), IR59418-7B-27-3 (G2), IR72593-B-13-3-3-1 (G12),
IR29 (G14), IR69588-4R-P-3-3 (G6) and IR72593-B-18-2-22 (G13) had the highest contribution to the Genotype $x$ Salinity interaction. Most of these genotypes also had the highest lack of correlation, which is the manifestation of the frequent rank changes. The global chi-square test on consistency of ranks is significant, indicating that the ranks of the 15 rice genotypes are inconsistent, the genotypes perform differently under different salinity levels; this is the cause of the significant Genotype $x$ Salinity levels interaction.

Various studies at different times on different species pointed out that this deduction could be associated with its adverse effect on yield related attributes. For instance, yield related traits such as panicle length, number of spikelet's per panicle, number of grains per panicle, and 100-grains weight showed a reduction with increase in root zone salinization but the effect varied in different rice genotypes. It was noted that terminal spikelet's appeared earlier under salt stress. Salinity stress tended to shorten the duration of spikelet differentiation, resulting in fewer spikelets per panicle [19, 14, 10]. These authors also concluded that salinity significantly decreased the number of spikelet primordia on the main spike. The florets in the basal spikelets appear to be significantly less viable than those in the apical spikelet's under saline conditions [13].

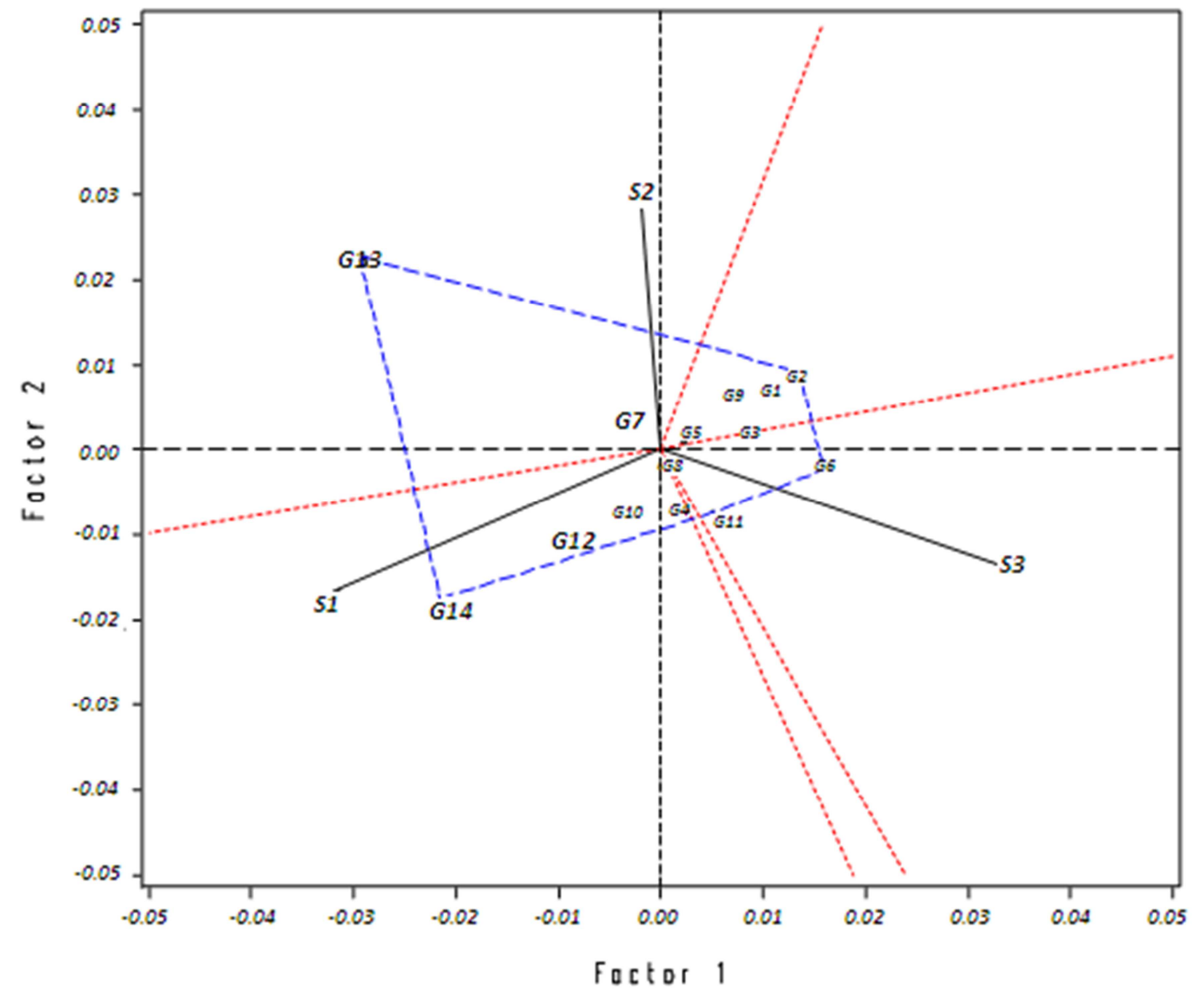

Figure 1. GGE biplot of 15 rice genotypes tested at three salinity levels. 


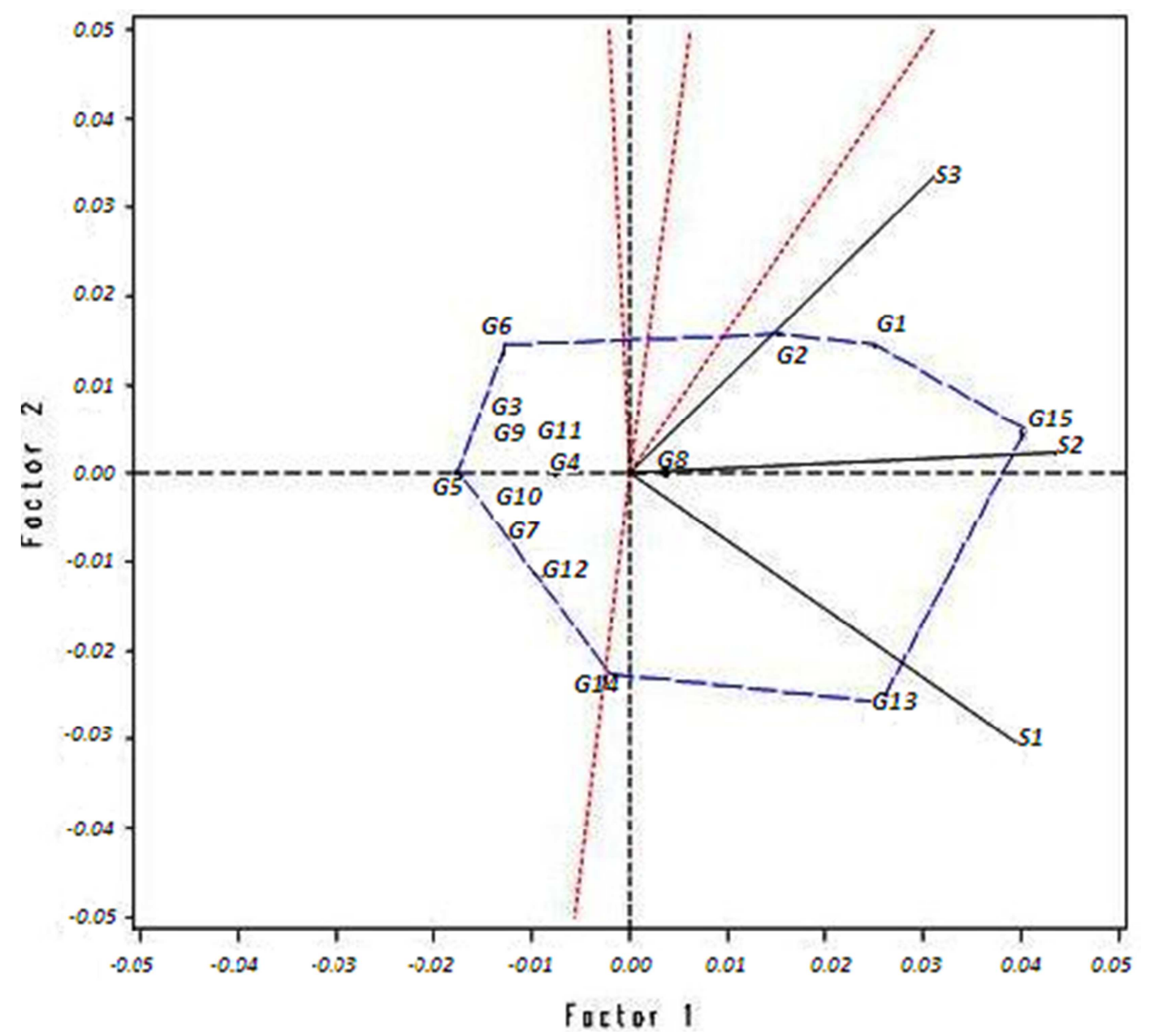

Figure 2. GxE biplot 15 Rice genotypes tested at different salinity levels.

Our results are in conformity with above findings; number of grains decreased with increased salinity and this effect was more pronounced in genotype IR61247-3B-8-2-1 (G3). Genotype IR68144-2B-2-2-3-3 (G9) followed by IR681442b-2-2-3-2 (G8) and IR66946-3R-176-1-1 (G15) gave significantly higher 100-grain weight than sensitive genotype IR29 (G14) even at $8 \mathrm{dSm}^{-1}$. Grain weight is largely determined by the duration and rate of grain filling $[18,26]$. Therefore, environmental stresses that tend to shorten the grain filling period will significantly reduce final grain weight [19]. Salt stress accelerates maturation and grain filling in some cereal crops [12,9]. Therefore, nearly consistent reduction in grain weight at the higher salinity levels could be the result of shortened grain filling period [10]. Effect of salinity was most pronounced on the yield components, which were developing later. Consequently, salinity deprived their contribution to grain yield. These results are supported by the work of [10] who stated that yield components which were stressed by salinity during their development contributed less to grain yield. Grain yield was also adversely affected by increasing salt levels in rice genotypes under study. Grain yield reduction in this study as a result of salinity was characterized by poor seed setting, reduced number of seeds and also lower grain weight as compared those of the control treatment. Poor seed setting characterized by sterile panicles is believed to be the consequence of pollen sterility in rice [1] and also in sorghum [4]. As compared to other plant attributes, grain yield per plant was more adversely affected by the two salinity levels in all genotypes, but the reduction was the same for all genotypes. Such results are also on the record in rice [2].

To elaborate more the adaptation of genotypes to different salinity levels we have used the GGE and GE biplots [5]. The GGE biplot captures both the genotypic and the GxE effects. This biplot of grain yield in grams per plant (Figure 2) puts all the three salinity levels (S1, S2 and S3 in Figure 2) into the same sector which lie between two lines perpendicular to the horizons of a polygon drawn through the highest values of the GGE effects. The winning genotypes in this sector are IR59418-7B-21-3 (G1), IR59418-7B-27-3 (G2), IR72593-B18-2-2-2 (G13), IR29 (G14), and IR66946-3R-176-1-1 (G15). However, it can be seen from the plot that IR29 (G14), and IR72593-B-18-2-2-2 (G13) are nearer to S1 (the control) and are the highest yielding under this salinity level; the GxE effect of IR66946-3R-176-1-1 (G15) under this salinity level is low (Figure 2). IR66946-3R-176-1-1 (G15) is the winning genotype under $\mathrm{S} 2\left(4 \mathrm{dSm}^{-1}\right)$ while IR59418-7B21-3 (G1) and IR61247-3B-8-2-1 (G3) are the winning genotypes under S3 $\left(8 \mathrm{dSm}^{-1}\right)$; The GxE effects of these two 
genotypes is very high here and more than compensates for the higher varietal effect of IR66946-3R-176-1-1 (G15), which has low GxE effect (less than 1/3 of IR59418-7B-21-3 (G1) and IR59418-7B-27-3 (G2)).

The GE biplot (Figure 3) which captures only the GE interaction effects distributes all the three salinity levels into different sectors. IR66946-3R-176-1-1 (G15) is again the winning genotype with the highest grain yield under S2, 4 $\mathrm{dSm}^{-1}$. IR29 (G14) is the winning genotype under S1, the control. IR59418-7B-27-3 (G2) and IR69588-4R-P-3-3 (G6) and to a lesser extent IR59418-7B-21-3 (G1) and IR72593-B13-3-2-1 (G11) are the winning genotypes under $\mathrm{S} 3,8 \mathrm{dSm}^{-1}$. Although the mean grain yields of IR69588-4R-P-3-3 (G6) and IR72593-B-13-3-2-1 (G11) are not high under S3,8 dSm${ }^{-1}$, these two genotypes have high $\mathrm{GxE}$ effects under this salinity level, as do IR59418-7B-21-3 (G1) and IR59418-7B-27-3 (G2).

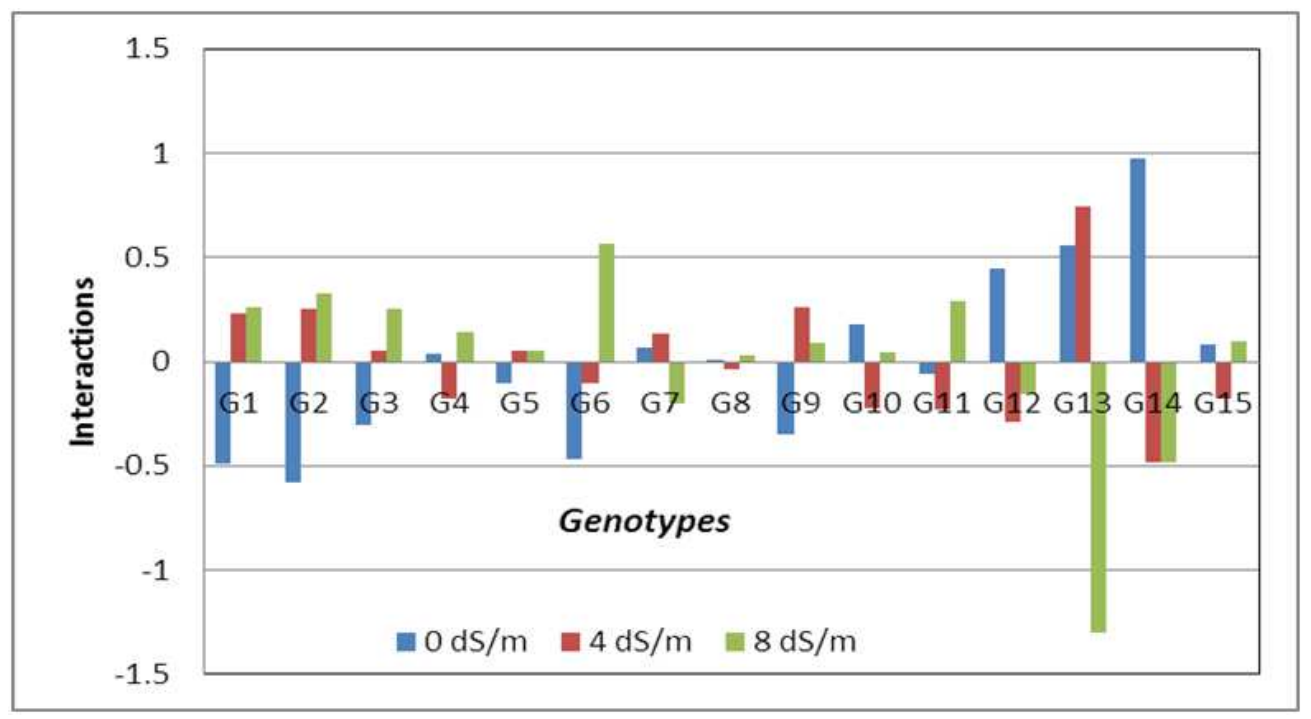

Figure 3. GxE effects on grain yield per plant of 15 rice genotypes tested across three root zone salinity level.

The GxS interaction results were plotted to see the interaction pattern of each line against the three salinity levels (Figure 3). Accordingly, the interaction plot depicted that TCCP266-1-3B-10-2-1 (G4), IR68652-3B-22-3 (G5), IR70870-B-P-2-2 (G7), IR68144-2B-2-2-3-2 (G8) and IR66946-3R-176-1-1 (G15) have very short bars, have minimum interaction with any of the three environments; The sum of the absolute value of the interaction effects, or the sum of their squares, which is Wricke's equivalence is minimal. Such genotypes are said to be stable and are adapted to all environments in the study. Such genotypes can be considered for use only if they have reasonable yields. Out of these, only IR68144-2B-2-2-3-2 (G8) and IR66946-3R176-1-1 (G15) have high yields.

\section{Conclusions}

It is evident from the results of this study that the root zone salinity levels of $8 \mathrm{dSm}^{-1}$ depressed the yield and yield components of all the genotypes under study. The magnitude of reduction varied not only for plant attributes but also the genotypes studied. This shows that genotypes of different genetic constitution show a differential reaction to salinity. The genotypes IR66946-3R-176-1-1 (G15), IR68144-2B-22-3-2 (G8), IR72593-B-18-2-2-2 (G13), IR59418-7B-21-3 (G1) and IR59418-7B-27-3 (G2) had high grain yield per plant. The salt-susceptible rice genotype, IR29 (G14) was found to be specifically adapted to non-saline growing conditions. Although there was a tendency for IR66946-3R176-1-1 (G15) to give high yield under $4 \mathrm{dSm}^{-1}$, this genotype was found to be stable and to give high grain yield per plant under almost all the three salinity levels. In this particular experiment, the correlation analysis showed that negative and highly significant association was revealed between salt concentration and grain yield, indicating the adverse effects of different salinity levels on yield potential of rice crop. Although variations were observed among exotic genotypes in the present studies, it would be worthwhile to evaluate more genotypes over years and across locations under salinity stressed and non-stressed conditions in order to identify more diverse genotypes / land-races and confirm their salt tolerance.

The linear - bilinear AMMI biplot, statistical analysis procedure has been adopted for complex agricultural experiments. However, the results of this study confirmed their potential application for simple experiments without a blocking factor. AMMI was found to be useful in discriminating potentially stable and tolerant lines against salinity.

\section{References}

[1] Akbar, M. and Yabuno, T. 1975. Breeding for salinity resistant varieties of rice. III. Response of F1 hybrids to salinity in reciprocal crosses between Jbona 349 and Mengolia. Japan J. Breeding. 25: 215-220. 
[2] Akbar, M., Sajjad, M. S. and Shakoor, A. 1979. Development of rice varieties for saline soils of Pakistan. Proc. Second National seminar on Rice Research and production, PARC, Pp: $79-84$

[3] Azhar, F. M. and McNeilly, T. 1987. Variability of salt tolerance in Sorghum bicolor (L.) Moench under hydroponic conditions. J. Agron., 159: 269-77.

[4] Azhar, F. M. and McNeilly, T. 1989. The response of four sorghum accessions/cultivars to salinity during plant development. Crop Sci., 63: 33-43.

[5] Burgueno, J., Crossa, J. and Vargas, M. 2001. SAS programs for graphing GE and GGE biplots. Biometrics and Statistics Unit, CIMMYT.

[6] Fentaw, A. 1995. Effects of subsurface drainage system on ground water table, soil salinity and crop yield in Melka Sadi Pilot drainage scheme. In: Woldeyesus Sinebo, Zerihun Tadele and Nigusie Alemayehu (Eds.), Increasing food production through improved crop management. Proceedings of the First and Inaugural Conference of the Agronomy and Crop Physiology of Ethiopia, 30-31 May 1995, IAR, Addis Ababa, Ethiopia, 139-148 pp.

[7] Flowers, T. J. and Yeo, A. R. 1981. Variability in the resistance of sodium chloride salinity within rice (Oryza sativa L.) varieties. New Phytol., 88: 363-373.

[8] Flowers, T. J. and Yeo, A. R. 1995. Breeding for salinity resistance in crop plants. Where next? Aust J Plant Physiol., $22,875-884$.

[9] Francois, L. E., Donovan, T. J., Maas, E. V. and Rubenthaler, G. L. 1988. Effect of salinity on grain yield and quality. Vegetative growth and germination of triticale. J. Agron., 80: $642-7$.

[10] Francoise, L. E., Grieve, C. M., Maas, E. V. and Lesch, S. M. 1994. Time of salt stress affects growth and yield components of irrigated wheat. J. Agron., 86: 100-7.

[11] Francois, L. E. and Klieman, R. 1990. Salinity effects on vegetative growth, seed yield and fatty acid composition of crabme. J. Agron., 82: 1110-14.

[12] Francois, L. E., Maas, E. V., Donovan, T. J. and Youngs, V. L. 1986. Effect of salinity on grain yield and quality, vegetative growth, and germination of semi-dwarf and Durum wheat. J. Agron., 78: 1053-1058.
[13] Grieve, C. M., Lesch, S. M., Francois, L. E. and Maas, E. V. 1992. Analysis of main spike and yield components in salt stressed wheat. Crop Sci., 32: 697-703.

[14] Grieve, C. M., Lesch, S. M., Maas, E. V. and Francois, L. E. 1993 Leaf and spikelet primordia initiation in salt-stressed wheat. Crop Sci. 33: 1286-1294.

[15] IRRI. 1997. Standard evaluation system for rice. International Rice Research Institute. Manila. Philippines.

[16] Khan, M. S., Hamid, A. and Karim, M. A. 1997. Effect of sodium chloride on germination and seedling characters of different types of rice (Oryza sativa L.). Crop Sci. 179: 163169.

[17] Kinfemichael G. 2005. Screening of some lowland teff accessions and varieties for $\mathrm{NaCl}$-induced salinity stress during germination and seedling stage. Journal pf Dryland Agri.. 84p.

[18] Kirby, E. J. M. 1974. Ear development in spring wheat. J. Agric. Sci., 82: 437-47.

[19] Maas, E. V. and Grieve, C. M. 1990. Spike and leaf development in salt stressed wheat. Crop Sci. 30: 1309-13.

[20] Munns, R. 2002. Comparative physiology of salt and water stress. Plant Cell and Environ., 25: 239-250.

[21] Pearson, G. A. and Bernstein, L. 1959. Salinity effects at several growth stages of rice. J. Agron., 51: 654-657.

[22] SAS. 2001. Statistical Analysis System for Windows, release 8. 02. SAS Institute Inc., Cary, NC.

[23] Szabolcs, I. 1979. Review of research on salt affected soils natural resources research XV, UNESCO, Paris.

[24] Szabolcs, I. 1989. Salt affected soils. CRS press. Inc., Boca Ratan, Florida. pp. 274.

[25] WARC (Werer Agricultural Research Centre). 2009. Annual Climate record at Werer Agricultural Research Center. Annual Report, Werer Agro meteorology Research Section, Werer, Ethiopia. 6p.

[26] Wardlaw, I. F., Sofield, I. and Cartwright, P. M. 1980. Factors limiting the rate of dry matter accumulation in the grain of wheat grown at high temperature. Aust J. Plant Physiol., 7: $387-400$. 